\title{
Process engineering advances in pharmaceutical and chemical industries: digital process design, advanced rectification and continuous filtration
}

DOI:

10.1016/j.coche.2019.02.005

\section{Document Version}

Accepted author manuscript

Link to publication record in Manchester Research Explorer

Citation for published version (APA):

Simon, L. L., Kiss, A., Cornevin, J., \& Gani, R. (2019). Process engineering advances in pharmaceutical and chemical industries: digital process design, advanced rectification and continuous filtration. Current Opinion in Chemical Engineering. https://doi.org/10.1016/j.coche.2019.02.005

Published in:

Current Opinion in Chemical Engineering

\section{Citing this paper}

Please note that where the full-text provided on Manchester Research Explorer is the Author Accepted Manuscript or Proof version this may differ from the final Published version. If citing, it is advised that you check and use the publisher's definitive version.

\section{General rights}

Copyright and moral rights for the publications made accessible in the Research Explorer are retained by the authors and/or other copyright owners and it is a condition of accessing publications that users recognise and abide by the legal requirements associated with these rights.

\section{Takedown policy}

If you believe that this document breaches copyright please refer to the University of Manchester's Takedown Procedures [http://man.ac.uk/04Y6Bo] or contact uml.scholarlycommunications@manchester.ac.uk providing relevant details, so we can investigate your claim.

\section{OPEN ACCESS}


Process engineering advances in pharmaceutical and chemical industries: digital process

Levente L. Simon ${ }^{1 *}$, Anton A. Kiss ${ }^{2,3}$, Jan Cornevin ${ }^{4}$, Rafiqul Gani ${ }^{5}$

${ }^{1}$ Syngenta Crop Protection AG, Process Technology New Active Ingredients, Breitenloh 5, 4333 Münchwilen, Switzerland

${ }^{2}$ School of Chemical Engineering and Analytical Science, The University of Manchester,

8 Sackville Street, Manchester, M13 9PL, United Kingdom. tony.kiss@ manchester.ac.uk

$9{ }^{3}$ Sustainable Process Technology Group, Faculty of Science and Technology, University of

10 Twente, PO Box 217, 7500 AE Enschede, The Netherlands

$11{ }^{4}$ Novartis Pharma AG, Continuous Manufacturing Unit, Novartis campus, Fabrikstrasse 2, 124002 Basel, Switzerland. jan.cornevin@ novartis.com

135 PSE for SPEED Company Ltd., Skyttemosen 6, DK-3450 Allerod, Denmark. 14 rgani2018@gmail.com.

* Corresponding author: levente.simon@syngenta.com, Tel: +41628685672

Highlights

Systematic digital reaction route selection, catalytic distillation, reactive distillation, continuous manufacturing, continuous filtration

\section{Abstract}

This review paper presents some of the topics discussed at the 2018 "Chemical process development trends" seminar organized by the Swiss Process and Chemical Engineers Society in Basel, Switzerland. The first subject covers the use of computer aided tools for systematic reaction route selection, the second one addresses the recent development in the field of process intensification with a focus on reactive distillation and dividing wall column technology and the third topic highlights recent developments in the field of continuous filtration in the pharmaceutical industry. 


\section{Introduction}

2 The "Chemical process development trends" seminar organized on $8^{\text {th }}$ November 2018 by the

3 Swiss Process and Chemical Engineers Society in Basel, Switzerland reviewed the recent

4 advances in selected pharmaceutical and chemical process technology areas. The seminar was

5 opened by Prof. R. Gani's talk from PSE for SPEED Company Ltd. on digital pharmaceutical

6 process design. This talk was followed by the contribution from D. Crettenand from RedElec

7 SA on the use of electrochemistry as a "green" technology in the field of organic synthesis.

8 Prof. A. Kiss from the University of Manchester presented an overview of recent advances in

9 the field of reactive distillation and dividing-wall column rectification while Prof. A. Zogg

10 gave a foresight of his future research portfolio at The University of Applied Sciences

11 Northwestern Switzerland. Recent advances on the use of continuous filtration in the context

12 of pharmaceutical manufacturing were highlighted by J. Cornevin from Novartis Pharma AG,

while R. De Dier from The Janssen Pharmaceutical Companies of Johnson \& Johnson

14 presented the model based lyophilization process optimization.

The aim of this review paper is to provide the broader chemical engineering community a deeper insight in some of the topics discussed at the seminar: the use of computer aided tools for systematic reaction route selection, recent reactive distillation and dividing wall column technology developments and continuous filtration implementation in the pharmaceutical industry.

\section{Digital process design methods for the pharmaceutical industry}

23 Methods and tools from process systems engineering (PSE), which are routinely used in the petrochemical and related industries, can also assist in the development, analysis, design, evaluation, and optimization of pharmaceutical processes. The scope and significance of these 
1 methods and tools depend on the available mathematical models and/or data. Even though the

2 final verification is always made through experiment-based studies, model-based computer3 aided systems can help to quickly evaluate and screen-out redundant processing options, to

4 select and verify solvents, to plan and design experiments and to quickly reduce the search 5 space related to reliable and efficient operation of the process operating in batch or continuous 6 mode. Recently, there has been an increasing interest in the development and/or application of 7 methods and tools from PSE for the pharmaceutical sector and among these, a model-based multi-functional computer-aided framework developed by Papadakis et al. [1] is worth

9 mentioning.

The framework aims to assist in the development of pharmaceutical processes by providing 11 detailed process understanding, selecting efficient reaction pathways through analysis of reactions, solid solubility analysis together with the need and use of solvents, and, identifying opportunities where continuous manufacturing might be an option. Systematic model-based methods and tools are applied in each step of the framework in order to create a data-rich environment that is a requirement for enhanced process understanding and to assist in the decision-making process in each case. To achieve these objectives, the framework integrates models and data, different model-based methods (defined by their specific work-flows and the associated data-flows for specific problems) and tools (that is, the tools that perform the needed work at each step of the work-flow). The integrated framework consists of four sections with their corresponding models, methods and computer-aided tools: reaction 21 pathway selection; reaction analysis; downstream separation analysis; and, process 22 simulation, evaluation, optimization and operation. An overview of the framework is illustrated in Fig. 1 (from Papadakis et al. [1]). 
2 Almost all pharmaceutical processes are based on some form of organic synthesis that defines 3 the reaction pathway, where organic chemistry has an important role to play in the

4 development of synthetic routes for new drugs during early stage process development. To 5 pursue synthesis at a high level, the needed access to chemical information is provided 6 through a specially developed reaction database and integrated within the framework. An 7 overview and extension of this database is presented below.

9 The reaction database [2] contains collected data for single and multiphase reactions involved 10 in small molecule pharmaceutical processes. The collected data are represented through a 11 specially developed ontology for knowledge representation. It has a search engine to retrieve necessary data when required for problem solution-analysis. The goal is to provide a data rich environment with process information available to assist during the early stage synthesis of pharmaceutical products. The reactions in the database are categorized according to the reaction type (for example, alkylation, epoxidation), the target product (active pharmaceutical ingredients like Ibuprofen, Ciproflexacin) to be produced (when single-step or multistep reactions are considered), the reaction product and the effect of the solvent used on the reacting system. Reaction conditions (temperature, pressure etc.), reaction components 19 (reagents, catalysts etc.), reaction data (conversion, selectivity, etc.), scaling information and 20 finally batch or continuous processing is included in the developed database. For each 21 reaction type, it is possible to,

- Identify reactions that are used to produce different types of products (API, 23 Intermediates).

24 - Identify reactions to be utilized, for a given compound availability.

25 - Investigate the function of different type of solvents in single/multiphase reactive systems. 
1 - Facilitate the choice of the reaction conditions.

2 - Evaluate the reaction pathway in terms of yield, cost and sustainability metrics.

3 - Facilitate the reactor design from available experimental data and kinetic models.

5 The individual reaction data are supplemented with information on scalability, cost, expected 6 yield, number of reaction steps, ease of separation and safety. The current version of the 7 database covers 44 reaction types consisting of 350 reactions where 88 represent multiphase 8 reaction systems and out of which 246 reactions involve the use of solvents (where the 9 objective is to dissolve, phase creation, substrate/catalyst carrier, compound extraction). The 10 total synthesis pathway data for 29 APIs and 25 building block chemicals are available. The 11 data collection covers 307 reactions with measured data on conversion, selectivity, reaction 12 yield, reaction conditions; 39 reaction systems with dynamic reaction data; 17 reaction 13 systems with details of published kinetic models; 112 reaction systems with in-flow data; for 14227 reactions systems with data for batch operations. The special physical properties data 15 cover 14 chemicals, 18 fine chemicals and 255 pharmaceuticals.

17 Each reaction is an individual record set in the database.

18 - Molecular structural information (Target product, by-products and substrates)

19 - Reaction centers (The collection of atoms and bonds that are changed during the reaction).

- Reaction system chemicals (Information of chemicals involved in the reaction such as 21 reagents, catalysts, solvents etc.)

22 - Multistep reactions (Products that require multiple reaction steps, that is, reaction 23 pathways)

- Reaction conditions (Conditions such as $\mathrm{pH}$, temperature, pressure etc., at which the reaction takes place) 
4 With the above information available and together with organic synthesis-design tools, an

- Reaction classification (Type of reaction, i.e., esterification, amination, etc.)

- Post-processing of the database contents (Export option to other tools) .

opportunity for an integrated approach to the synthesis route selection and productivity improvement taking into account process considerations (development time to establish the synthesis route, product quality, cost of manufacture linked to "green" chemistry metrics and the final approval of regulatory agencies) is now possible. One starting point on the use of the reaction database is the molecular structure of the API. The search engine of the database will check if reaction data for this API are available. If yes, the related data are retrieved through the search engine interface for further analysis as outlined in the work-flow of the framework [1]. If the data are not available, the properties of the API are predicted through associated property prediction tools available in the framework [1]. For the generation of the synthesis routes, Papadakis et al [2] give a detailed list of databases and systematic methods and tools based on artificial intelligence that may be employed. Other starting points are classes of reactions or specific reactants. With the synthesis routes established, the reaction database will determine the equilibrium constants for each reaction step and then suggest the minimum reaction data that would be needed to identify an appropriate kinetic model together with a list of corresponding experiments. Once all the necessary data are made available, the reaction and process evaluation are performed as outlined in the work-flow of the framework. It should be noted that the database contains collected data of known reacting systems, therefore, for new systems, data either need to be generated or collected. The search engine of the database points to the minimum data that are needed for any analysis and how the data could be obtained. 
1 The application of the database is illustrated through the synthesis of ibuprofen, for which,

2 data for three different reaction pathways are retrieved from the database and the production 3 processes compared using the "green" chemistry metrics [2].

\subsection{Solvent Selection and Database}

6 Solvent selection is part of the framework section dealing with downstream separation analysis. The complexity of product recovery and purification is related to the compounds present in the final reaction mixture. The selection of appropriate downstream separation tasks in terms of total number of operations needed, solvent requirements, operational costs, and sustainability, effect process performance and therefore, feasibility. In addition, due to the complexity of the main product, operational limitations are taken into account in order to define the design space of the separation operations. Methods and computer-aided tools for improvement of process efficiency through the use of solvents in multiphase and single-phase reactions [3] as well as solvents for crystallization [4], solvent based extractions [5] are studied through the solvent selection and design toolbox [6] available as an in-house tool within the framework [1]. The methods and tools available in the framework allows options for process intensification in terms of integration of reaction-separation tasks, minimization of reaction steps and solvent swapping options.

\subsection{Simulation, evaluation, optimization and operation}

21 The objective here is to evaluate process flowsheets (or state task network) with respect to 22 predefined performance criteria and identified targets for further process optimization and improvement. Available methods and tools allow the design and evaluation of PAT systems, study of crystallization operations, and study of process operations, including feasibility of converting batch operations to continuous modes. Note that different kinds of models and 
1 model- and/or data-based analyses are needed for study of different aspects of pharmaceutical

2 processes. Continuous or batch pharmaceutical process evaluation requires conventional

3 single scale models based on mass and energy balance that are usually available in process

4 simulators and also available in the framework [1]. However, since the pharmaceutical

5 product also needs to satisfy product quality requirements, higher resolution models and/or

6 online data are needed for product quality monitoring through an appropriate PAT system

7 [19]. Here, multiscale models for crystal size distribution, crystal shape, effect of operational

8 parameters, etc., need to be considered. This model-data based analysis is needed in addition

9 to analysis of simulation results based on mass and energy balance for a complete evaluation

10 of pharmaceutical processes. Papadakis et al. [7] provides an interesting illustration of model-

11 based methods and tools for design and analysis of an industrial glucose isomerization

12 process operation.

\section{Process intensification technologies}

Process Intensification (PI) is defined as a set of novel innovative principles applied in process and equipment design, which can bring significant benefits in terms of process and chain efficiency, lower capital and operating expenses, higher quality of products, less wastes and improved process safety. In other words it helps chemical engineers to achieve more (e.g. higher performance and efficiency) with less equipment and energy. Novel methods have been proposed recently for the and systematic process design and intensification, based on new representation of process units, flowsheets and superstructures using fundamental building blocks [8]. Such a general block-based superstructure allows the systematic identification of process intensification pathways.

Among PI technologies proposed, the most promising ones are in the functional (synergy) 
1 synergistic effects to overcome equilibrium limitations, leading to compact equipment and

2 increase of overall efficiency. The PI area is expanding rapidly with tremendous support from

3 industry, having a strong impact and significance for the development of more eco-efficient

4 processes (see the RAPID institute in US). The scope of PI covers many technologies [9], but

5 here we focus only on the most promising ones: reactive distillation and dividing-wall

6 column, Figure 2. These PI techniques are able to simplify complex configurations, and thus

7 reduce the numbers of steps required for reaction and separation stages.

\subsection{Reactive distillation technology}

Reactive distillation (RD) allows the reaction and distillation to take place at the same time in

the single piece of equipment; the reactants being converted with the simultaneous separation of the products. By overcoming equilibrium limitations, RD brings ample process economic benefits, as it enhances the productivity and selectivity, reduces the energy use, eliminates the need for solvents, and intensifies the mass and heat transfer [10]. Moreover, RD simplifies complex process configurations and reduces the overall costs by half or more. For example, in case of methyl acetate synthesis a RD column replaced a conventional process consisting of 10 key units ( 1 reactor, 8 distillation columns and 1 extraction column), allowing $80 \%$ savings in energy and capital costs.

Although RD has been implemented as high-efficiency systems in the large scale petrochemical industry, more recently the RD technology found novel applications in the batch-tocontinuous transition and synthesis of many products from the specialty chemicals, fine chemicals and pharma sectors: e.g. esters, ethers, monomers and polymers [11]. Remarkable, reactive distillation could be further enhanced by combining it with other intensified technologies - such as dividing-wall column, cyclic distillation, high-gravity distillation, heat- 
1 distillation - to lead to the development of new processes and applications, particularly

2 aiming at smaller scale of 10 ktpy or less [12].

3

\subsection{Dividing-wall column technology}

Dividing-wall column (DWC) found great appeal in the chemical industry as it offers major benefits: $25-40 \%$ lower energy requirements, high purity for all product streams, reduced maintenance costs, $40 \%$ smaller small footprint and up to $30 \%$ lower investment costs due to the reduced number of equipment units. Thermodynamically equivalent to Petlyuk distillation or fully thermally coupled distillation, DWC can replace a direct or indirect sequence of distillation columns by a more energetically-favorable configuration that avoids the remixing of internal streams. Details about the specific internals of DWC are available at equipment suppliers (www.montz.de) and in recent review papers [13], [14]. Although DWC is mainly applied to ternary separations, more recent applications and research directions include the use of DWC technology in azeotropic, extractive, and reactive distillation [15] ${ }^{* *},[16]$, for example in the production of bio-alcohols, ethers, or furfural. By using an adaptable and flexible modular approach, the DWC can be applied in multi-purpose production scale and downstream processing of fine chemicals and pharmaceuticals. For example, Lonza has recently implemented in Visp, Switzerland, a flexible DWC that meets the demands of a changing production characterized by several production campaigns, processes and products produced in the same plant throughout a year [17].

\section{Filtration technologies in the context of continuous manufacturing}

Manufacturing in the pharmaceutical industry is presently almost entirely dictated by batch processes. This is the result of decades of strongly regulated historical batch processing. Nevertheless, there is a strong incentive to shift from batch to continuous manufacturing of 
1 active pharmaceutical ingredients (APIs) and to leverage the advantages of steady-state

2 operation [18]. Although pharma is a highly regulated and largely batch-oriented industry, the

3 use of novel continuous manufacturing can lead to innovative products and help pharma

4 companies resolve some long-standing issues related to cost, quality inspection, and supply

5 chain. With an increased interest both from the industry, academia and regulatory bodies over

6 the last 10 years [19], companies have adopted different approaches to integrate the process

7 analytical technology [20] based continuous manufacturing technology in their

8 manufacturing lines. While a lot of $R \& D$ has been focusing on continuous reaction and

9 crystallization design, operation and control [20], little has been dealing with the interface

10 between these two manufacturing clusters namely continuous isolation. This is because

11 continuous isolation for APIs, e.g. continuous filtration, is a major technical challenge and

12 involves the use of less established technologies. Nevertheless, recently, the versatility,

13 flexibility and efficiency of continuous filtration has raised the interest of companies.

14 The current approaches to continuous filtration taken by R\&D organizations can be clustered

15 into two main strategies: automated batch filtration [21] and continuous flow filtration [22] ${ }^{* *}$,

16 Figure $3 \mathrm{a}$ and $3 \mathrm{~b}$. While the former is based on the well-established Nutsche filtration and is

17 mainly an automation exercise, the latter requires integrating a less common technology to

18 pharmaceutical development that is the cross flow filtration (CFF), which is a standard

19 technology for the biotechnology industry. In both cases though, the main challenge lies in the

20 fact that little to no continuous filtration equipment is designed to the standards of the

21 pharmaceutical industry e.g. Good Manufacturing Practices (GMP), which triggers significant

22 and cost intensive technology development and qualification efforts.

23 To best compare these two processes one has to consider in which context these will be

24 implemented. A Nutsche continuous filtration will produce a cake with ca. $20-30 \%$ of residual

25 moisture content, which is subsequently dried and analyzed. In comparison a CFF process 
1 will produce a well flowing concentrated suspension (wet paste) which is suited for further

2 processing [23]. While the cake filtration rate is dependent on the API crystal shape, which

3 can vary from product to product, the CFF is less dependent on it, thus makes it a more

4 versatile process. One should note that washing in CFF is consuming much more solvent than

5 the Nutsche filtration. This disadvantage increases when equipment is scaled-up. Furthermore,

6 CFF filtration can be easily integrated within continuous manufacturing and will leverage its

7 advantages when coupled with other continuous processes. However, it can be also be a versatile filtration process coupled to classical batch manufacturing steps.

\section{Outlook}

The main challenge for methods and tools from PSE for applications in the pharmaceutical industry is how to provide reliable process understanding through the available data and models that are employed? With new chemicals being continuously synthesized, clearly, reliable predictive models and data analysis tools are needed together with a data collection system that is continuously extended with availability of new data. The objective here is not to provide the final optimal solution through these model-data based methods-tools, but to quickly reduce the search space so that the product development time and cost can be significantly and reliably reduced.

The main challenges of applying PI technologies such as reactive distillation and dividingwall column to the production of fine chemicals and pharmaceuticals relate to ensuring

21 sufficient modularity and flexibility in a low production scale multi-product environment, as a higher degree of process integration comes at reduced flexibility in operation. Such PI techniques can aid the batch-to-continuous transition by properly adapting them to multipurpose production scale and downstream processing of fine chemicals and pharmaceuticals. 
1 Regarding the routine use of continuous filtration in the pharmaceutical industry future

2 challenges are related to equipment standardization of equipment and adequate process 3 control.

Acknowledgements

6 AAK gratefully acknowledges the Royal Society Wolfson Research Merit Award.

7 JC acknowledges Novartis Pharma AG, Basel for financial support.

9 'Declarations of interest: none'.

\section{References}

[1] E. Papadakis, J.M. Woodley, R. Gani, Chapter 24 - Perspective on PSE in

This article describes the details of the reaction database framework.

[3] T. Zhou, Z. Lyu, Z. Qi, K. Sundmacher, Robust design of optimal solvents for chemical reactions-A combined experimental and computational strategy, Chem. Eng. Sci. (2015). doi:10.1016/j.ces.2015.07.010.

[4] A.T. Karunanithi, L.E.K. Achenie, R. Gani, A computer-aided molecular design framework for crystallization solvent design, Chem. Eng. Sci. 61 (2006) 1247-1260. doi:10.1016/j.ces.2005.08.031. 
1 [5] I. Mitrofanov, S. Sansonetti, J. Abildskov, G. Sin, R. Gani, The Solvent Selection framework: solvents for organic synthesis, separation processes and ionic liquids solvents, Comput. Aided Chem. Eng. 30 (2012) 762-766. doi:10.1016/B978-0-44459520-1.50011-7.

[6] E. Papadakis, A.K. Tula, R. Gani, Solvent selection methodology for pharmaceutical processes: Solvent swap, Chem. Eng. Res. Des. 115 (2016) 443-461. doi:https://doi.org/10.1016/j.cherd.2016.09.004.

[7] E. Papadakis, S. Pedersen, A.K. Tula, M. Fedorova, J.M. Woodley, R. Gani, Modelbased design and analysis of glucose isomerization process operation, Comput. Chem. Eng. 98 (2017) 128-142. doi:https://doi.org/10.1016/j.compchemeng.2016.12.016.

[8] S.E. Demirel, J. Li, M.M.F. Hasan, Systematic process intensification using building blocks, Comput. $\quad$ Chem. $\quad$ Eng. $105 \quad$ (2017) 2-38. doi:10.1016/j.compchemeng.2017.01.044.

[9] A.A. Kiss, Process intensification: Industrial applications, in: Process Intensif. Chem. Eng. Des. Optim. Control, 2016: pp. 221-260. doi:10.1007/978-3-319-28392-0_8.

[10] A.A. Kiss, Process intensification by reactive distillation, in: Process Synth. Process Intensif. Methodol. Approaches, 2017: pp. 143-181. doi:10.1515/9783110465068-004.

[11] A.A. Kiss, Novel Catalytic Reactive Distillation Processes for a Sustainable Chemical Industry, Top. Catal. (2018) 1-17. doi:10.1007/s11244-018-1052-9.

[12] A.A.. J. Kiss M.; Gao X., Reactive distillation: Stepping up to the next level of process intensification, Ind. Eng. Chem. Res. (2019). doi:10.1021/acs.iecr.8b05450.

[13] I. Dejanović, L. Matijašević, Ž. Olujić, Dividing wall column-A breakthrough towards sustainable distilling, Chem. Eng. Process. Process Intensif. 49 (2010) 559-580. doi:10.1016/j.cep.2010.04.001.

[14] O. Yildirim, A.A. Kiss, E.Y. Kenig, Dividing wall columns in chemical process 
industry: A review on current activities, Sep. Purif. Technol. 80 (2011) 403-417. doi:10.1016/j.seppur.2011.05.009.

This is an outstanding review that focuses on the industrial use of dividing wall columns with applications in ternary separations, as well as azeotropic, extractive, and reactive distillation. It also covers key issues related to DWC configurations, process control, process design and simulation.

[15] A.A. Kiss, Advanced Distillation Technologies: Design, Control and Applications, John Wiley \& Sons, Ltd, 2013. doi:10.1002/9781118543702.

[16] J.A. Weinfeld, S.A. Owens, R.B. Eldridge, Reactive dividing wall columns: A comprehensive review, Chem. Eng. Process. Process Intensif. 123 (2018) 20-33. doi:10.1016/j.cep.2017.10.019.

[17] D. Staak, T. Grützner, B. Schwegler, D. Roederer, Dividing wall column for industrial multi purpose use, Chem. Eng. Process. Process Intensif. 75 (2014) 48-57. doi:10.1016/j.cep.2013.10.007.

[18] L.L. Simon, Continuous manufacturing: Is the process mean stationary?, AIChE J. 64 (2018) 2426-2437. doi:10.1002/aic.16125.

[19] K. Nepveux, J.-P. Sherlock, M. Futran, M. Thien, M. Krumme, How Development and Manufacturing Will Need to Be Structured - Heads of Development/Manufacturing May 20-21, 2014 Continuous Manufacturing Symposium, J. Pharm. Sci. 104 (2015) 850-864. doi:10.1002/jps.24286.

[20] L.L. Simon, H. Pataki, G. Marosi, F. Meemken, K. Hungerbühler, A. Baiker, S. Tummala, B. Glennon, M. Kuentz, G. Steele, H.J.M. Kramer, J.W. Rydzak, Z. Chen, J. Morris, F. Kjell, R. Singh, R. Gani, K.V. Gernaey, M. Louhi-Kultanen, J. Oreilly, N. Sandler, O. Antikainen, J. Yliruusi, P. Frohberg, J. Ulrich, R.D. Braatz, T. Leyssens, M. Von Stosch, R. Oliveira, R.B.H. Tan, H. Wu, M. Khan, D. Ogrady, A. Pandey, R. Westra, E. Delle-Case, D. Pape, D. Angelosante, Y. Maret, O. Steiger, M. Lenner, K. 
Abbou-Oucherif, Z.K. Nagy, J.D. Litster, V.K. Kamaraju, M.-S. Chiu, Assessment of recent process analytical technology (PAT) trends: A multiauthor review, Org. Process Res. Dev. 19 (2015) 3-62. doi:10.1021/op500261y.

[21] S. Ottoboni, C.J. Price, C. Steven, E. Meehan, A. Barton, P. Firth, A. Mitchell, F. Tahir, Development of a Novel Continuous Filtration Unit for Pharmaceutical Process Development and Manufacturing, J. Pharm. Sci. 108 (2019) 372-381. doi:10.1016/j.xphs.2018.07.005.

[22] J. Gursch, R. Hohl, G. Toschkoff, D. Dujmovic, J. Brozio, M. Krumme, N. Rasenack, J. Khinast, Continuous Processing of Active Pharmaceutical Ingredients Suspensions via Dynamic Cross-Flow Filtration, J. Pharm. Sci. 104 (2015) 3481-3489.

This article describes the details of the cross-flow filtration evaluation in the pharmaceutical industry.

[23] A. Schmidt, H. de Waard, K.-P. Moll, P. Kleinebudde, M. Krumme, Simplified end-toend continuous manufacturing by feeding API suspensions in twin-screw wet granulation, Eur. J. Pharm. Biopharm. $133 \quad$ (2018) 224-231. doi:https://doi.org/10.1016/j.ejpb.2018.09.026.

\section{Figures}

Figure 1. Integrated systematic framework to assist the pharmaceutical process development.

Figure 2. Configurations for reactive distillation (top) and dividing-wall column (bottom)

Figure 3 Two continuous filtration strategies, a CFF from Bokela (a) and an automated Nutsche filtration (b) from Alconbury Weston Ltd. 


\section{General framework to enhance process \\ understanding during the early stage \\ chemical/bio/pharma process development}

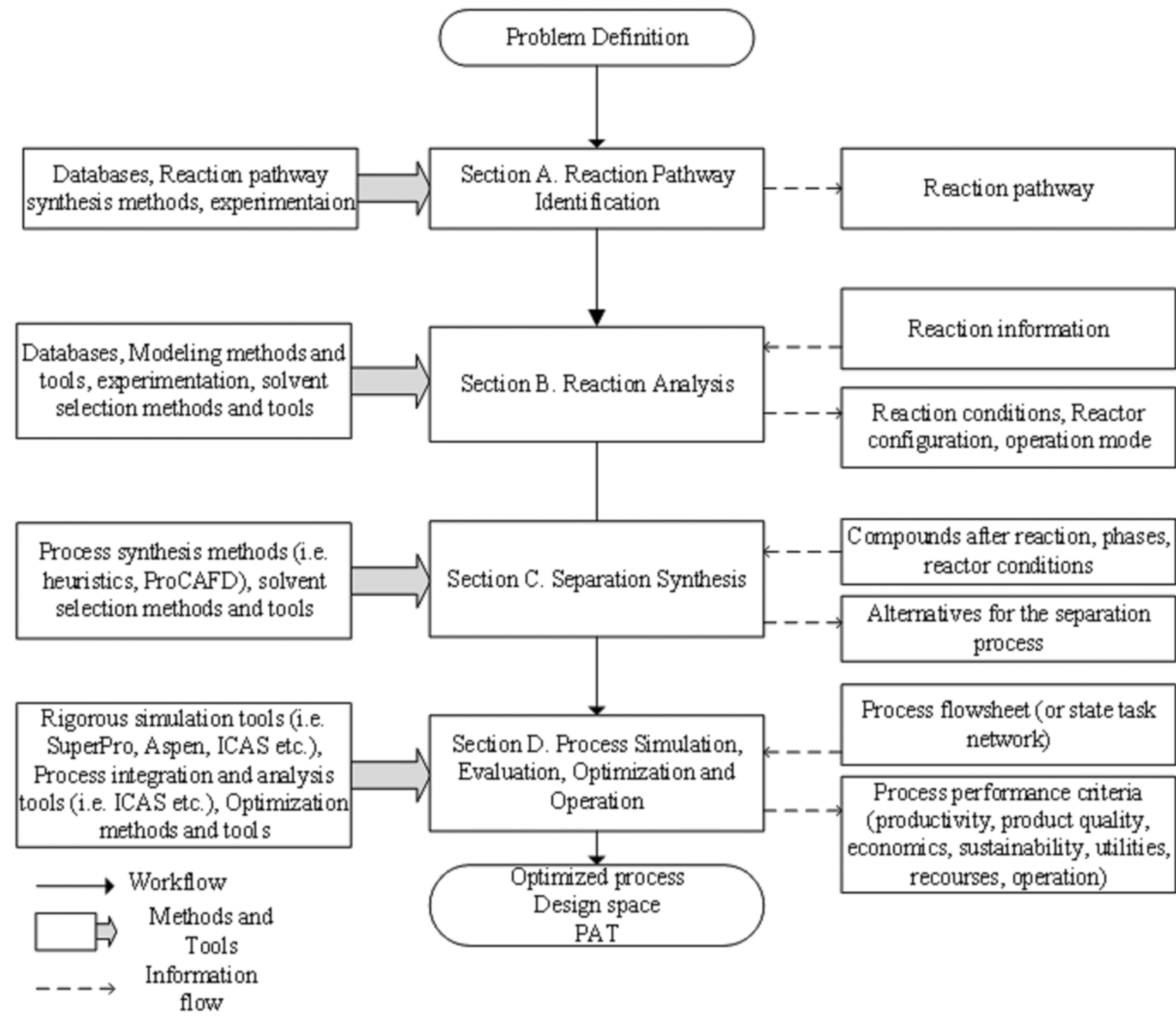




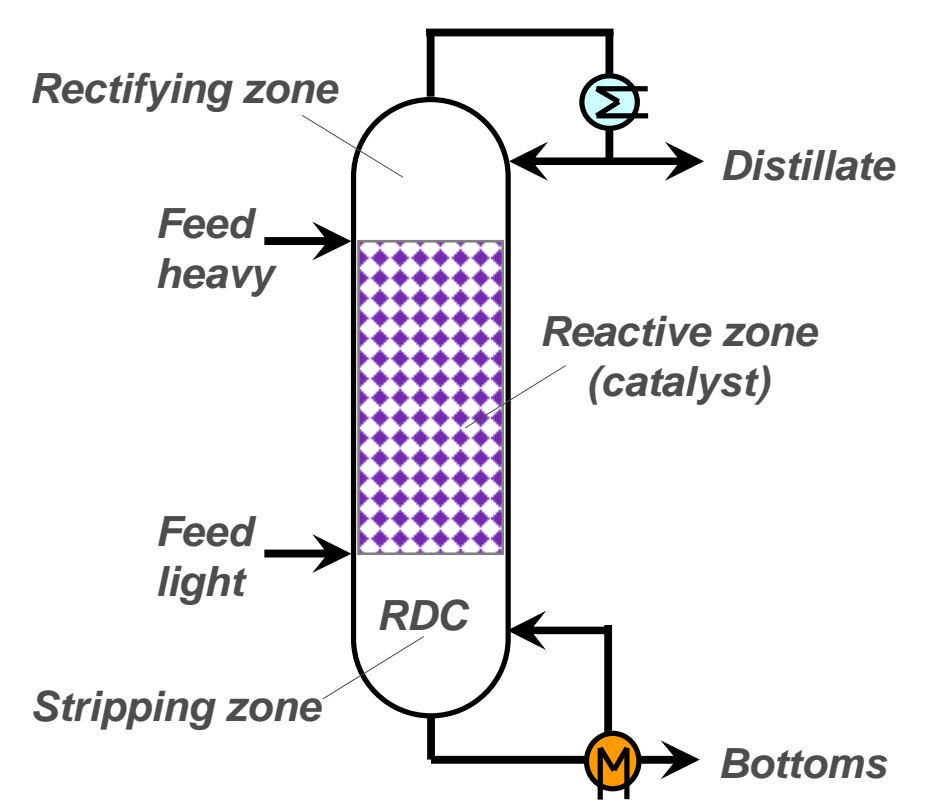

Reactive distillation column

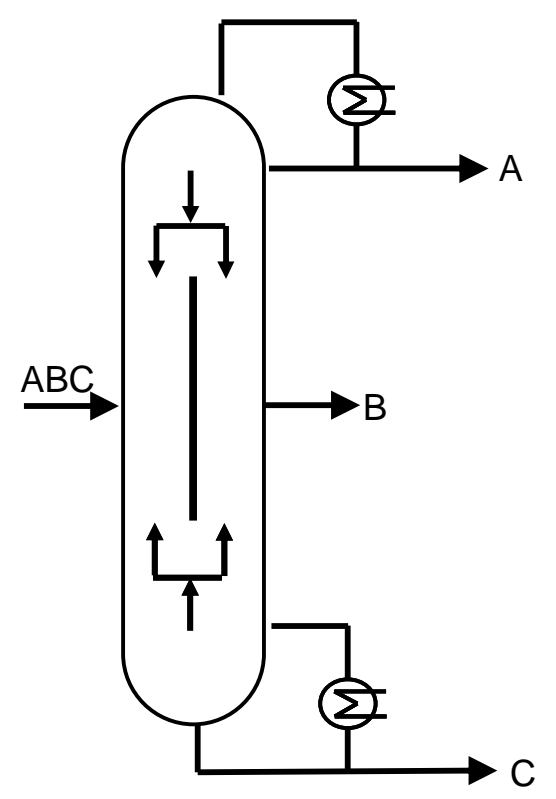

Dividing-wall column

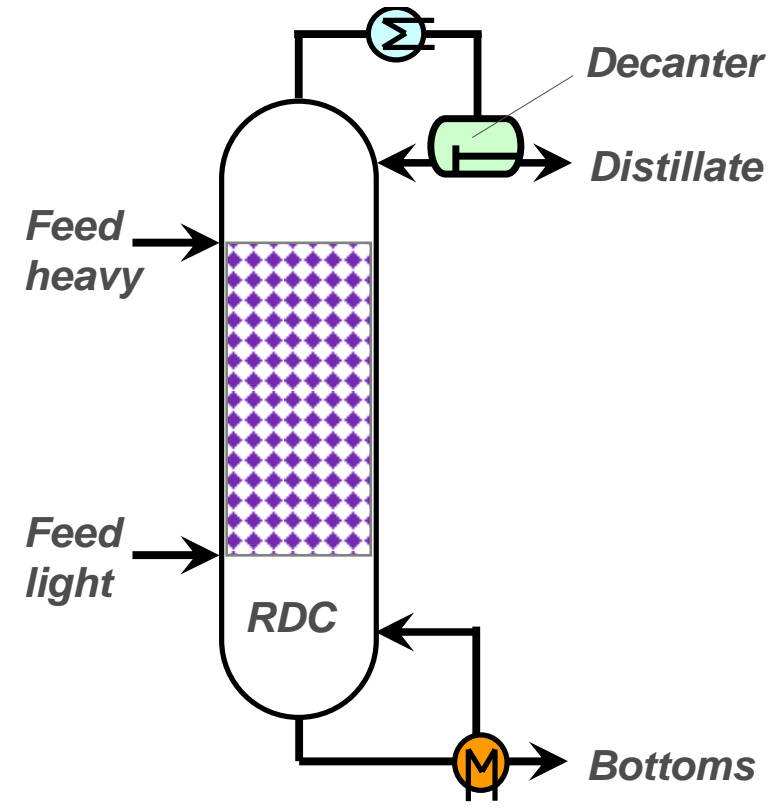

Heterogeneous azeotropic RD

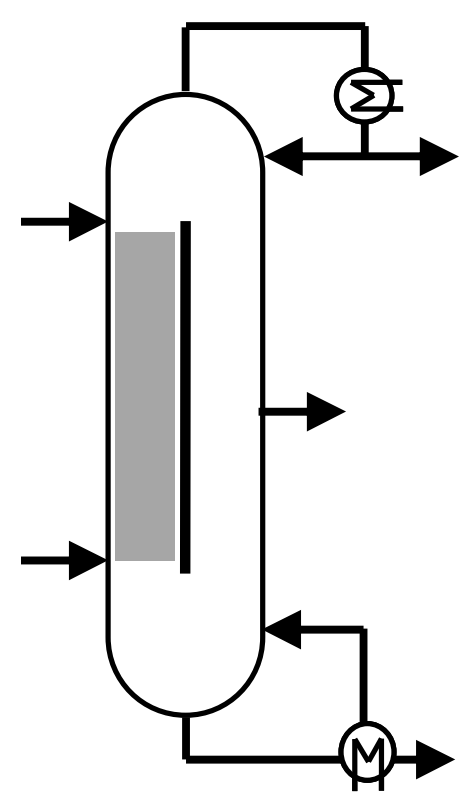

Reactive DWC

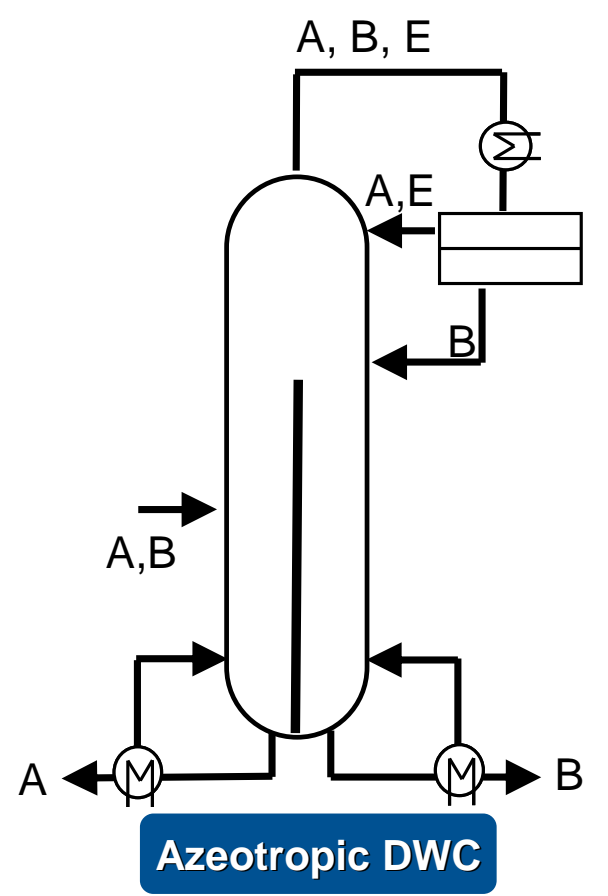

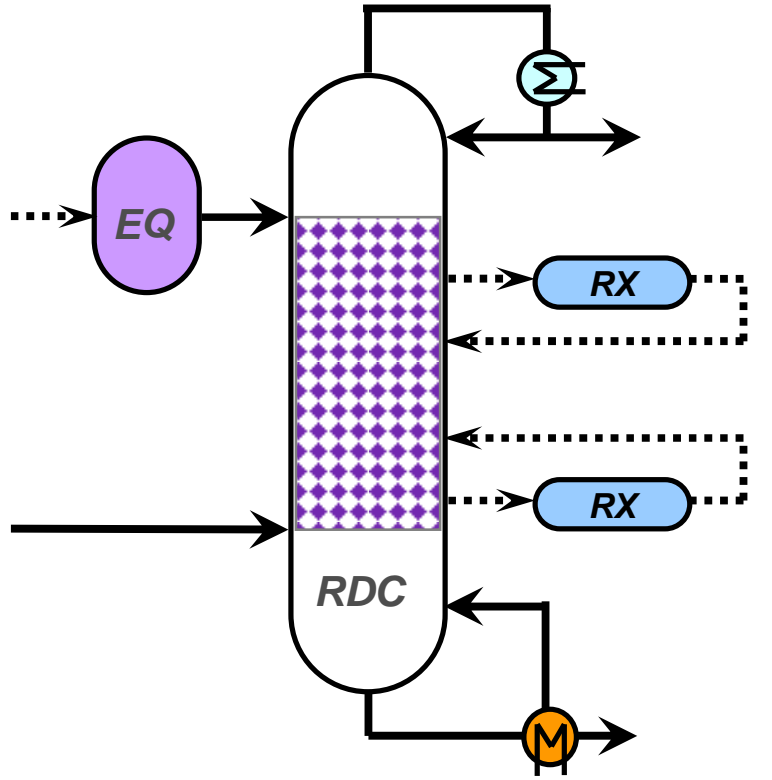

RD with pre-reactor \& side reactors

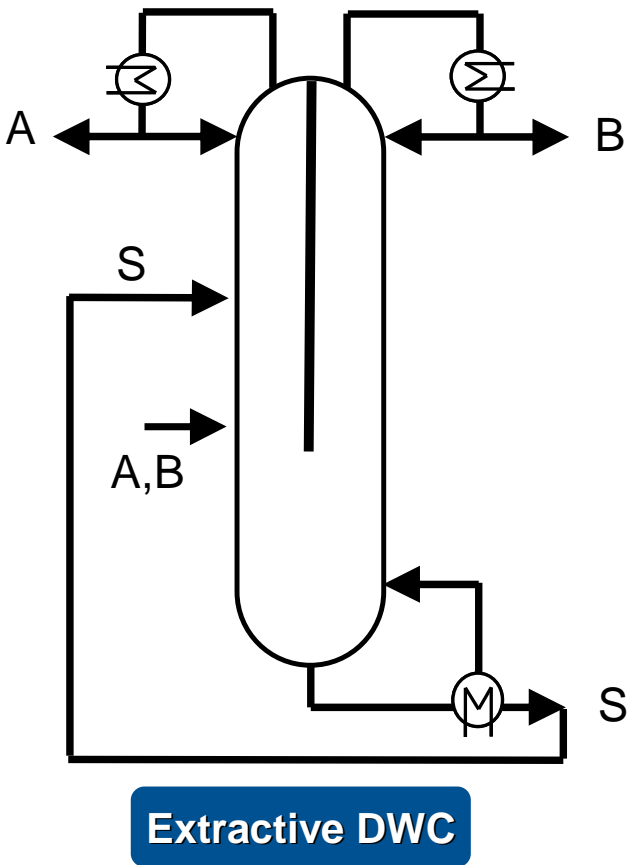



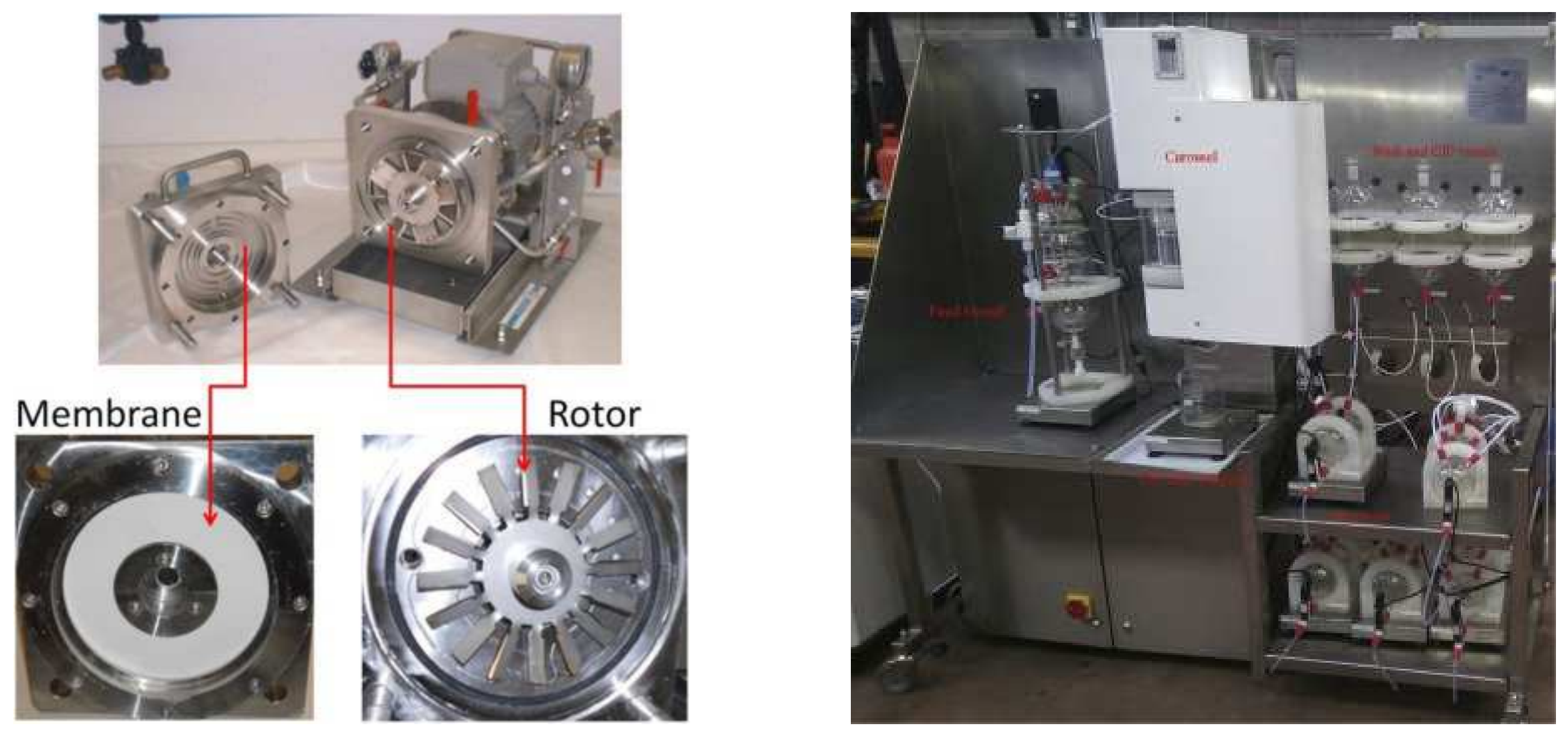

Figure 3 